\title{
Study and Investigation of the Effects of the OTA Technique on the Physical Properties of the ZnO Thin Films Prepared by PLD
}

\author{
Duha S. Hassan, Mehdi Q. Zayer* \\ Department of Applied Science, University of Technology - Iraq
}

\section{Article information}

Article history:

Received: June, 10, 2021

Accepted: October, 10, 2021

Available online: December, 04, 2021

Keywords:

OTA Effect,

Physical properties,

$\mathrm{ZnO}$ film

*Corresponding Author:

Mehdi Q. Zayer

100320@uotechnology.edu.iq

\begin{abstract}
The polycrystalline thin films were deposited on glass substrate at room temperature by pulsed laser deposition PLD technique. The effects of annealing treatment by used the Oil Thermal Annealing (OTA) process on the structural, optical and electrical properties of $\mathrm{ZnO}$ thin film films were investigated. The film structure was investigated by X-ray diffraction to indicate that the heat treatment after the OTA process gives the optimized condition of crystalline. The transmission spectrum of the film was measured by UV-V is spectrophotometer, and the Urbach energy and forbidden band width were calculated. The surface topography of the film was observed by scanning electron microscopy (SEM) image of the $\mathrm{ZnO}$ thin film at the OTA process shows the changes in the shape and size of the grains. The atomic force microscopy (AFM) effect of heat treatment was demonstrated by the change in the surface roughness of the $\mathrm{ZnO}$ thin film. The electrical properties of thin film were optioned by Hall Effect technique. That these improvements in the $\mathrm{ZnO}$ thin film physical properties were annealing temperatures by OTA at $150{ }^{\circ} \mathrm{C}, 200{ }^{\circ} \mathrm{C}, 250{ }^{\circ} \mathrm{C}$ and $300{ }^{\circ} \mathrm{C}$.
\end{abstract}

DOI: 10.53293/jasn.2021.3805.1045, Department of Applied Science, University of Technology

This is an open access article under the CC BY 4.0 License

\section{Introduction}

Zinc oxide is a binding energy semiconductor n-type with a direct bandgap of about $(3.37 \mathrm{eV})$ and has interesting optical and electrical properties at room temperature It has been shown that $\mathrm{ZnO}$ thin films possess good electrical conductivity and high optical transmittance $[1,2]$. $\mathrm{ZnO}$ thin film can be prepared at several preparation techniques, such as Pulsed laser deposition, chemical spraying, chemical vapor deposition, ion-beam assisted deposition, and reactive evaporation [1-3]. There are many problems when using some of these techniques to prepare high-quality $\mathrm{ZnO}$ thin films. The pulsed laser deposition method was chosen as the preparation method. Pulsed laser deposition (PLD) is one of the best methods for growing high-quality, oriented c-axis $\mathrm{ZnO}$ thin film at low temperatures. The pulsed laser deposition technique is an ideal choice for the preparation of $\mathrm{ZnO}$ thin film on the glass substrate because of its high rate of good adhesion and easy control of the film thickness [4-6]. Because of the important features of the $\mathrm{ZnO}$ thin film, it has been preferred over silicon in the manufacture of solar cells, it has given good results [7]. ZnO thin film provides motivation advantages for a wide field of applications, gas sensors, displays, and photovoltaic devices [8-12]. Previous experiments have found that the physical properties of the $\mathrm{ZnO}$ thin film change significantly during the deposition process as well as the heat treatment. Therefore, physical properties such as structural, morphological, optical, and electrical are closely related to the preparation conditions and heat treatment [13-18]. The experiments in the previous studies showed that heat treatment has an important role in 
improving the optical and structural properties of $\mathrm{ZnO}$ thin films [19]. This work aims to improve the physical properties of $\mathrm{ZnO}$ thin film through heat treatment. The heat treatment parameters were changed and verified to improve the physical properties of the $\mathrm{ZnO}$ thin film.

\section{Theoretical}

The pellet target of Zinc oxide powder was prepared by a hydraulic press. The material of powder $\mathrm{ZnO}(99,99 \%)$ was cold-pressed by using a hydraulic press of 5 tons. The resulting pellet has homogenous surface on both sides with $25 \mathrm{~mm}$ diameter and $4 \mathrm{~mm}$ thickness of $\mathrm{ZnO}$ target. The Pyrex glass as substrate was used for deposits $\mathrm{ZnO}$ thin film. There are two steps before using the glass substrate at deposition process to preparing for work. Firstly, it was cut into small slides in $(25 \times 25) \mathrm{mm} 2$ dimensions. Secondly, it was cleaned with ethanol and ultrasonically and finally heated at $50{ }^{\circ} \mathrm{C}$. ZnO thin film was prepared on the glass substrate by the manufactured system with PLD technique at parameters of Nd: YAG laser, wavelength $\lambda=1064 \mathrm{~nm}$. And pulse power (400) mJ. The machine manufactured by Shenyang Scientific Instrument Research Institute. The substrate was Pyrex glass, Argon gas used as space surrounding the sample after vacuum obtained at 10-3 Torr at room temperature.

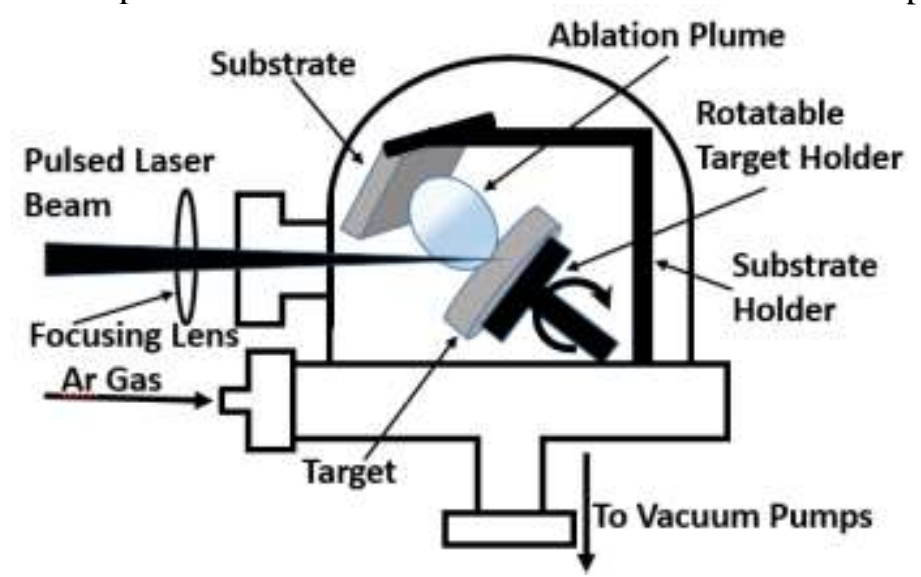

Figure 1: PLA Setup diagram with $\mathrm{ZnO}$ target during deposition on the glass substrate.

The thermal oil type used in the OTA technique in this work is DOWTHERM ${ }^{\mathrm{TM}}$. That's oil has a high heat transfer performance at temperatures from $15{ }^{\circ} \mathrm{C}$ to $400{ }^{\circ} \mathrm{C}$. OTA process treatment stages start after the sample is placed inside the quartz container and filled with thermal oil, then heating until the desired temperatures reach are 150 ${ }^{0} \mathrm{C}, 200{ }^{0} \mathrm{C}, 250{ }^{\circ} \mathrm{C}$, and $300{ }^{\circ} \mathrm{C}$. After completing the heat treatment, the sample is left inside same the oil until cools, then extract the sample. The sample cleaned with n-Hexane C6H14, which has been chosen not to affect the physical properties of the film and its ability to good removes oil.

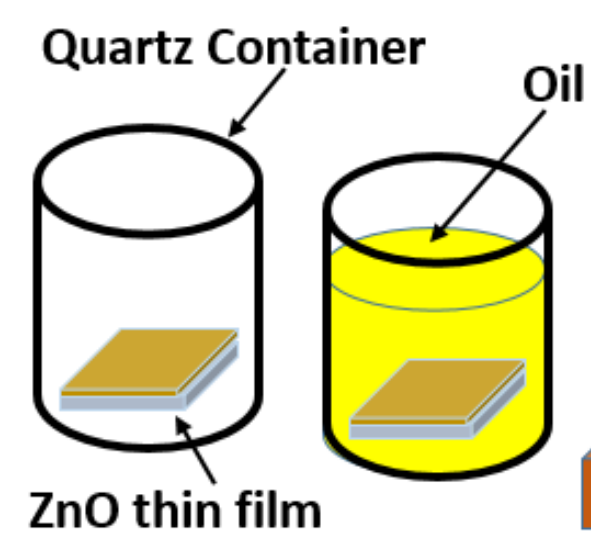

(a) (b)

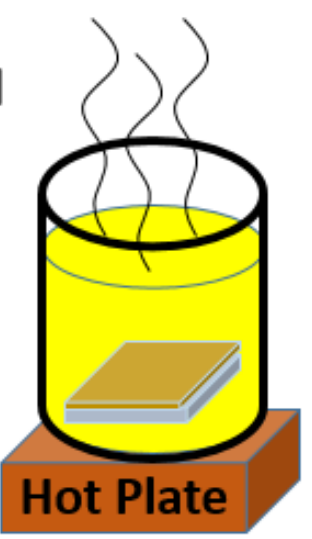

(c)

Figure 2: OTA process diagram of the stages treatment a) Putting sample inside the container b) Fill the container with oil c) Oil heat to the desired temperature. 
The sample was XRD-tested by X-ray diffractometer, and the film thickness was $200 \mathrm{~nm}$, measured by an XP-2 type step meter manufactured by AMBIOS, USA. The transmission spectrum of the sample was tested by a UV 2100 spectrophotometer manufactured by Shimadzu Corporation. The microscopic morphology of the sample was tested by scanning electron microscopy.

\section{Results and Discussion}

Physical properties study of $\mathrm{ZnO}$ polycrystalline thin films prepared by PLD technique, which are morphological, structural, optical and electrical. The properties of the $\mathrm{ZnO}$ thin films are closely related to the annealing temperature treatment. The treatment by OTA process was at four temperatures are $150{ }^{\circ} \mathrm{C}, 200{ }^{\circ} \mathrm{C}, 250{ }^{\circ} \mathrm{C}$ and $300{ }^{\circ} \mathrm{C}$, which agree with [20].

\subsection{Morphological Properties}

\subsubsection{SEM analysis}

Figure 3 SEM images indicate the effect of annealing treatment by OTA process on the ZnO thin film compared with the as-deposited sample. The film deposited at room temperature then treatment annealed arrive about to 300 ${ }^{\circ} \mathrm{C}$ is fuller than the grain before annealing, the grain boundary is clear, the uniformity and compactness of the film are improved, and the film is smoother and denser. Where observed that annealing treatment a clearer topography as the increases temperature. The as-deposited sample compared with the annealing temperature at $150{ }^{\circ} \mathrm{C}$ observe little change. Change is gradually increasing very clearly when compared with other annealing temperatures $200{ }^{\circ} \mathrm{C}, 250{ }^{\circ} \mathrm{C}$, and $300{ }^{\circ} \mathrm{C}$ respectively. That the surface of the deposited film at room temperature is rough, the bonding between the crystal grains is loose, the pinholes are large, and the grain shape is irregular. The $\mathrm{ZnO}$ thin film at $300{ }^{\circ} \mathrm{C}$ is a large change in the distribution of the dense grains. The properties are improved, although there is some grain size is not consistent. That the atoms in the film get higher energy when raising the temperature, for this reason, is migrate and recrystallize. 

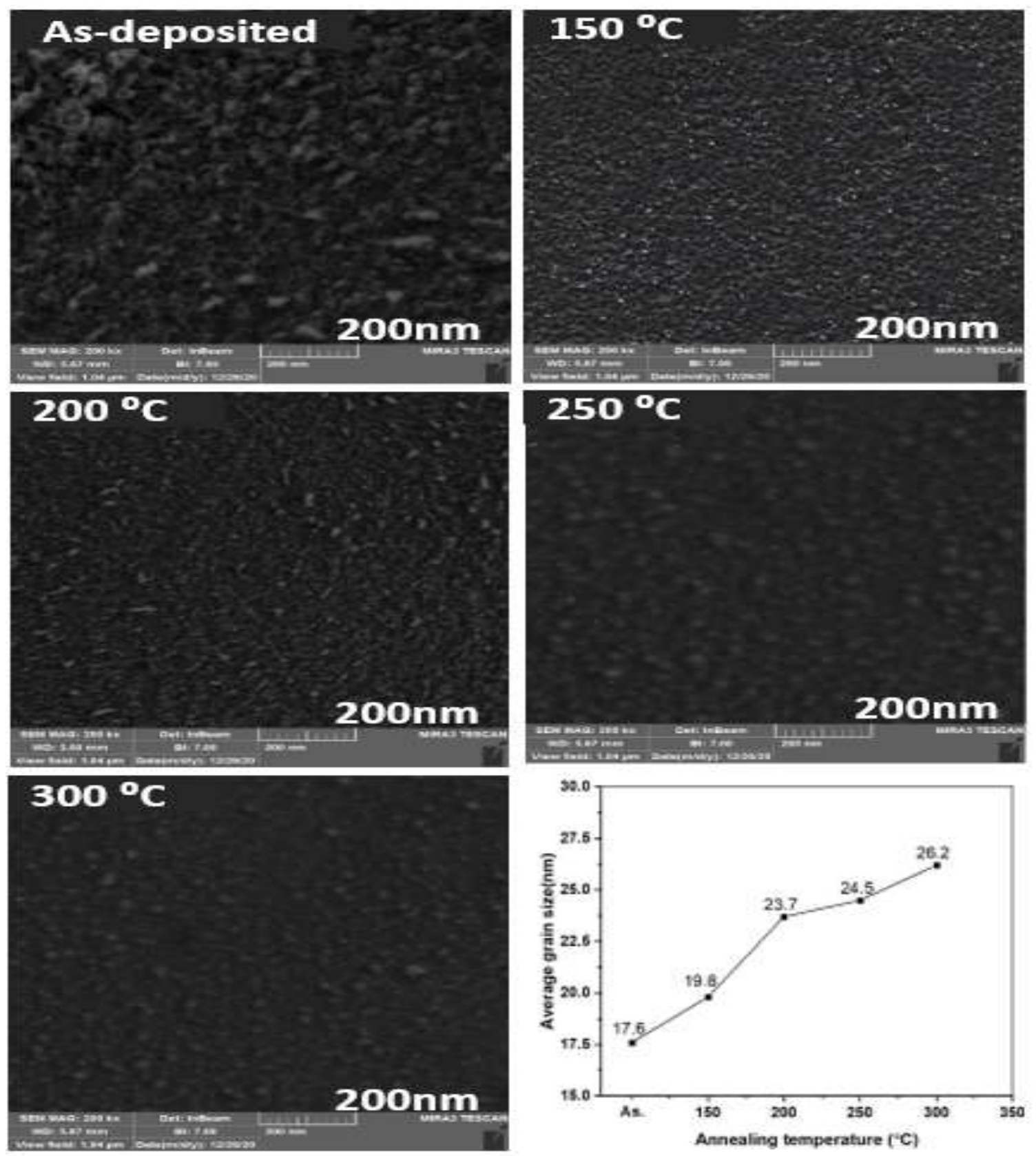

Figure 3: SEM images of the $\mathrm{ZnO}$ thin film before and after treatment by the OTA technique

\subsubsection{AFM atomic Force microscopy analysis}

Figure 4 shows three-dimensional AFM images before and after annealing by the OTA technique at temperatures $150{ }^{\circ} \mathrm{C}, 200{ }^{\circ} \mathrm{C}, 250{ }^{\circ} \mathrm{C}$, and $300{ }^{\circ} \mathrm{C}$ respectively. The surface morphology of $\mathrm{ZnO}$ thin film, which has been verified by AFM, clearly indicates that polycrystalline. The roughness decrease on the $\mathrm{ZnO}$ thin film surface clear ranging from $30-59 \mathrm{~nm}$ depending on the increase of the annealing temperature. The film that was heat-treated at $300{ }^{\circ} \mathrm{C}$ shows ovals with layers' parallel to the surface and the small peaks that appear at temperatures of 150 ${ }^{\circ} \mathrm{C}, 200{ }^{\circ} \mathrm{C}$ and $250{ }^{\circ} \mathrm{C}$ cannot be found. 

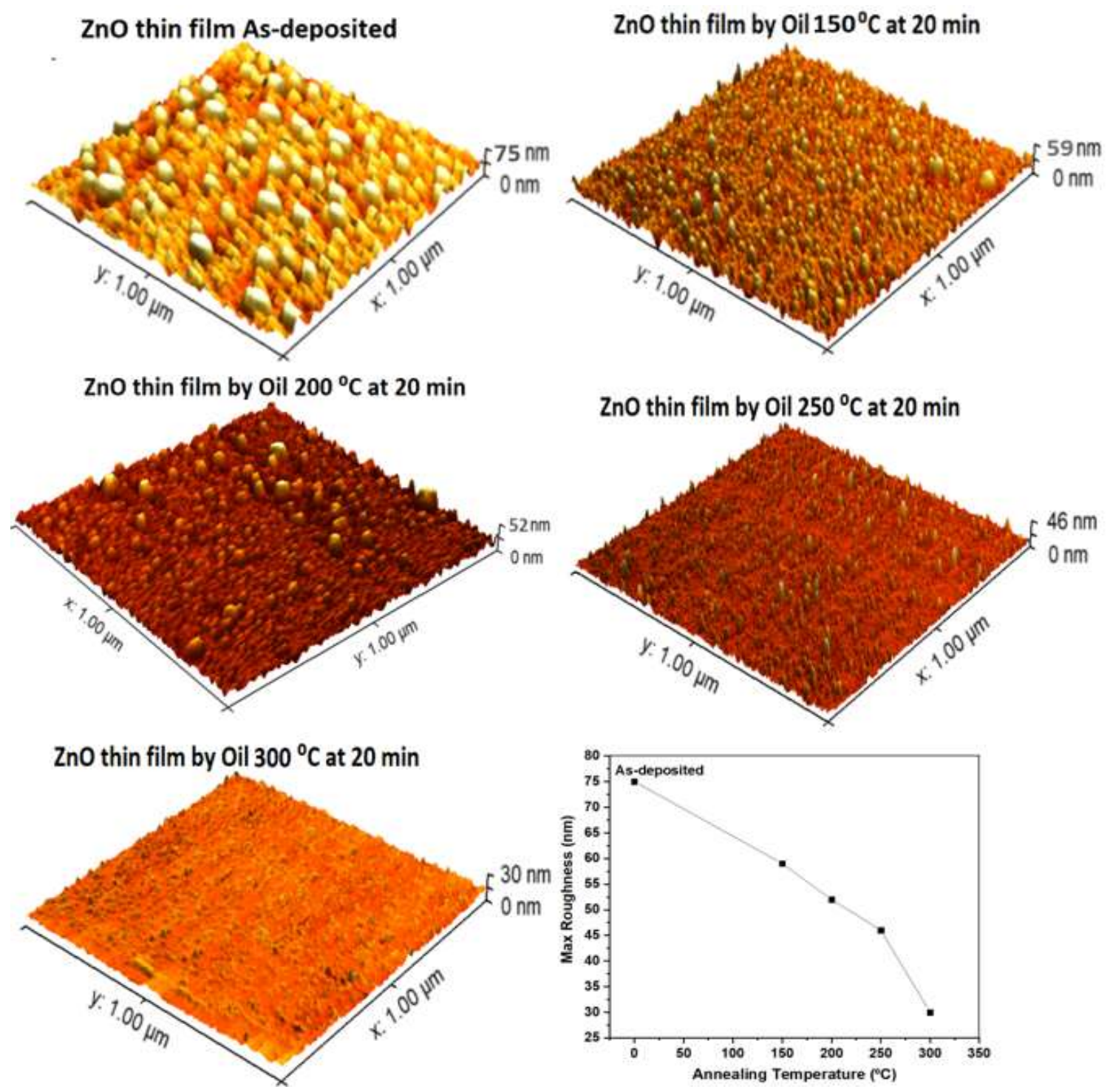

Figure 4: AFM images of the $\mathrm{ZnO}$ thin film before and after treatment by the OTA technique.

\subsection{Structural Analysis}

Figure 5 shows the $\mathrm{X}$-ray diffraction spectrum of a $\mathrm{ZnO}$ thin film prepared at room temperature on the glass substrate by the PLD technique. The heat treatment was carried out through the OTA process to obtain an improvement in the structural properties. Heat treatment by the OTA process is under different temperatures at $150,200,250$, and 300 . The $\mathrm{ZnO}$ film observed is annealed at $300^{\circ} \mathrm{C}$ within $20 \mathrm{mn}$ defects, better microstructure. The $\mathrm{ZnO}$ crystal has two forms of wurtzite structure $\alpha-\mathrm{ZnO}$ and sphalerite structure $\beta-\mathrm{ZnO}$. It can be seen from Figure 1 that the films in this experiment are all hexagonal $\alpha-\mathrm{ZnO}$. There are three prominent diffraction peaks which are (002), (001), and (110). The film has a distinct preferred orientation in the (002) direction with increased annealing temperature. When increasing the heat treatment, the preferred orientation (002), (001), and (110) crystal plane increases. The diffraction peak intensity has a significant deviation at (002), (001), and (110), but the diffraction peak at other orientations weakened. This offset is related to the internal structure affected by the heat treatment. 


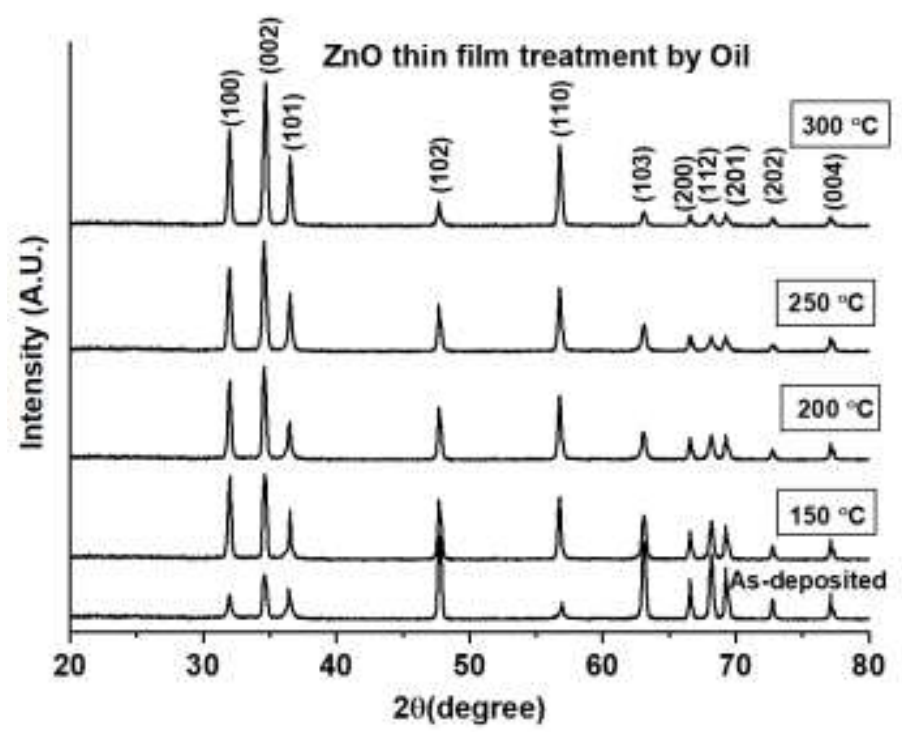

Figure 5: X-ray diffraction spectrum of the $\mathrm{ZnO}$ thin film before and after treatment by the OTA technique

Table 1 lists the $\mathrm{ZnO}$ film treatment by the OTA technique at temperatures 150200250300 . Diffraction peak angle position, crystal plane distance, full width at half maximum, and stress. The film sample has a certain shift from the peak position to the high diffraction intensity compared with the peak position of the As-deposited sample. As the working pressure increases, the offset angle increases, and the inter-planar spacing changes. It can be seen that the $\mathrm{ZnO}$ thin film has a certain shift from the peak position to the high diffraction intensity compared with the other peak of the As-deposited sample, and as the annealing temperature increases, the offset angle increases, and the inter-planar spacing changes. The peak position shift of the film sample indicates that the film has internal stress, which causes the crystal lattice to be stretched or compressed. According to the film property formula, the film stress can be calculated by measuring the crystal lattice distortion, which agrees with [10].

Table 1. Relationship between microstructure parameters and deposition pressure of $\mathrm{ZnO}$ thin films.

\begin{tabular}{|c|c|c|}
\hline $\begin{array}{l}\text { Annealing Temperature } \\
\qquad\left({ }^{0} \mathrm{C}\right)\end{array}$ & Average Grain size (nm) & $\begin{array}{l}\text { Orientation \& } \\
2 \theta \text { (degree) }\end{array}$ \\
\hline $\begin{array}{l}\text { As. } \\
150\end{array}$ & $\begin{array}{l}17.6 \\
19.8\end{array}$ & \multirow{4}{*}{$\begin{array}{l}(100)_{31.96^{\circ}},(002)_{34.6^{\circ}},(101)_{36.4^{\circ}},(102)_{47.72^{\circ}}, \\
(110)_{56.92^{\circ}},(103)_{63.08^{\circ}},(200)_{66.6^{\circ}},(112)_{68.16^{\circ}}, \\
(201)_{69.24^{\circ}},(202)_{72.67^{\circ}},(004)_{77.12^{\circ}}\end{array}$} \\
\hline 200 & 23.7 & \\
\hline 250 & 24.5 & \\
\hline 300 & 26.2 & \\
\hline
\end{tabular}

\subsection{Optical Properties}

\subsubsection{Urbach with Band energy calculation}

The lattice defects of the $\mathrm{ZnO}$ film can be reflected in the tail of the absorption band and can be characterized by the Urbach energy. The change of the energy of the Urbach is consistent with the change of the defect density of the film, and the density of the film is large. If the energy is small, the defect density is small. According to the Urbach rule, the absorption coefficient $\alpha$ of the film and the photon energy hv are satisfied near the absorption edge.

$$
\alpha=\alpha_{0} \exp ^{\left(\frac{h v}{E_{u}}\right)}
$$


Where $\mathrm{Eu}$ is Urbach energy, $\alpha_{0}$ is a constant, and the absorption coefficient $\alpha$ can be calculated from the transmission spectrum.

$$
\alpha=-\ln \frac{(T)}{d}
$$

Where $\mathrm{T}$ is the transmittance and $\mathrm{d}$ is the film thickness. From (2), it can be seen that $\ln \alpha$ has a linear relationship with photon energy, and Urbach energy is the reciprocal of the slope of the linear part, as shown in Figure 6.

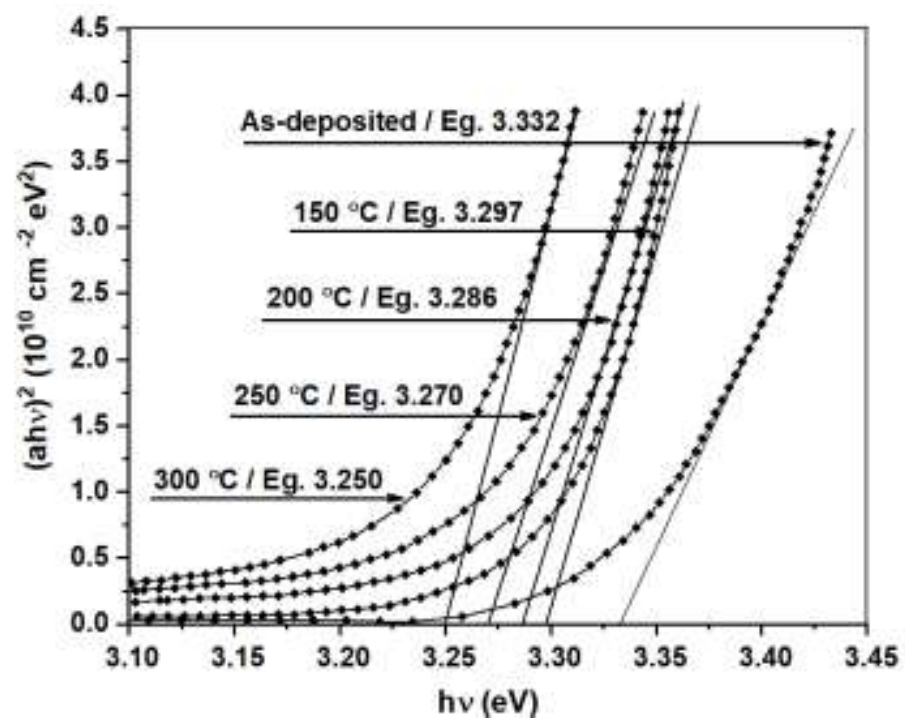

Figure 6: Determination of the $\mathrm{ZnO}$ thin film Band gap from the Urbach energy.

Figure $6 \mathrm{ZnO}$ thin film (ahv) and photon energy curve compared with $(h v)$ at annealing temperatures $150{ }^{\circ} \mathrm{C}, 200$ ${ }^{\circ} \mathrm{C}, 250{ }^{\circ} \mathrm{C}$ and $300{ }^{\circ} \mathrm{C}$. The relationship between the bandgap and Urbach energy of $\mathrm{ZnO}$ thin film after annealing treatment show that the bandgap decreased with the annealing temperature. That confirms that as the annealing temperature increases, the film improvement increases, and defects decreased. The intercept of the absorption edge tangent on the abscissa is the optical energy gap. The annealed sample at $300{ }^{\circ} \mathrm{C}$ was the forbidden bandwidth Eg $=3.28 \mathrm{eV}$, which is consistent with the wurtzite $\mathrm{ZnO}$.

Since $\mathrm{ZnO}$ is a direct bandgap semiconductor, its absorption coefficient and energy gap satisfy the Tauc formula.

$$
(\alpha h v)^{2}=A\left(h v-E_{g}\right)
$$

Where $\mathrm{h} v$ is the photon energy, Eg is the forbidden band width, A is a constant, and $\alpha$ is the absorption coefficient. A relationship diagram of $(\alpha h v) 2-h v$ is made, as shown in Figure 7. 


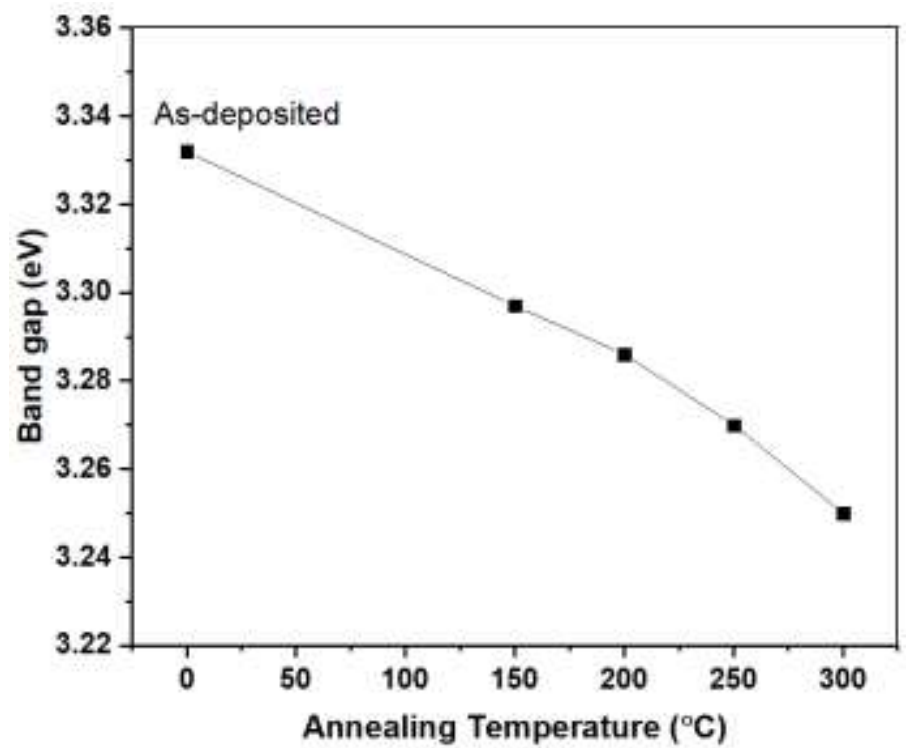

Figure 7: Variation of the bandgap of $\mathrm{ZnO}$ film with annealing temperature

\subsubsection{Transmittance Spectrum Analysis}

Figure 8 shows the transmission spectra of $\mathrm{ZnO}$ films at $200 \mathrm{~nm}$ thickness with heat treatment by different temperatures are $150{ }^{\circ} \mathrm{C}, 200{ }^{\circ} \mathrm{C}, 250{ }^{\circ} \mathrm{C}$, and $300{ }^{\circ} \mathrm{C}$. The film deposited by the PLD technique has a significant redshift in the absorption edge to the presence of defects caused during preparation, including the forbidden narrowed bandwidth. Some of these defects include the vacancies between the atoms caused by the molecule's vaporization and then deposited on the glass substrate. The thickness is at the lower deposition is larger than the upper this leads to interference phenomenon occurs because the thickness is smaller than the visible wavelength, there is no interference fluctuation. In addition, when the annealing temperature is $300^{\circ} \mathrm{C}$, the absorption edge of the film is steep, indicating the film has good crystal quality. After annealing at $300{ }^{\circ} \mathrm{C}$ for $20 \mathrm{~min}$, the transmittance is higher, and the transmittance is above $94 \%$ in the wavelength range of $450-900 \mathrm{~nm}$.

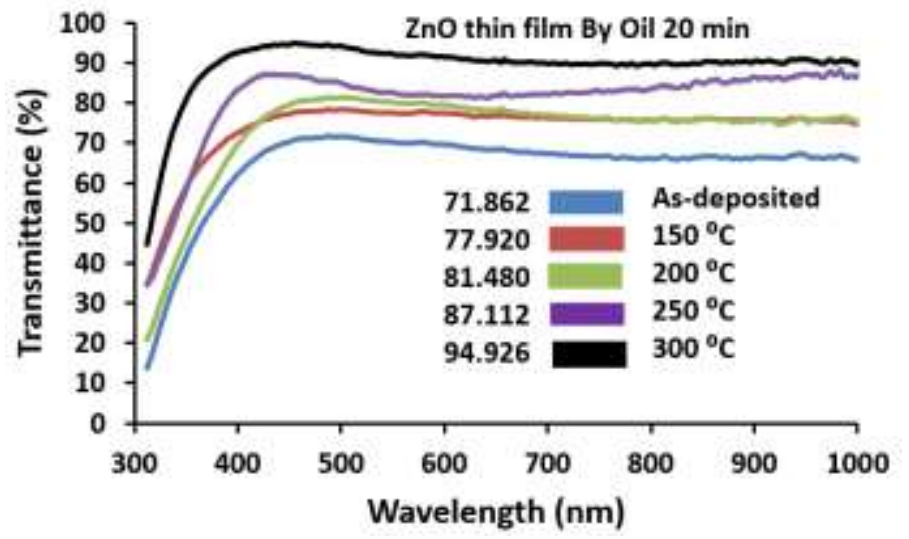

Figure 8: shows the Transmittance curve of $\mathrm{ZnO}$ film before and after annealing by OTA technique at $150{ }^{\circ} \mathrm{C}$, $200{ }^{\circ} \mathrm{C}, 250{ }^{\circ} \mathrm{C}$, and $300{ }^{\circ} \mathrm{C}$.

\subsection{Electrical Properties}

Figure 9 shows the relationship between the effect of annealing temperature on resistivity and Hall mobility. It may be clear that the relationship of the annealing temperature with the resistivity is inverse proportioned, while with the Hall mobility it is a direct proportion. Hall's Effect theorem was used to measure the electrical properties of the film treated by the OTA technique. The Carrier concentration (n) and Hall mobility ( $\mu$ ) of the grown $\mathrm{ZnO}$ 
thin films have been measure on the glass substrate, which electrical and temperature parameters as shown in table 2. The variation of electrical parameters explains a similar trend over a wide temperature shown in table (2), in which $\mathrm{h}$ eat treatment caused an order of magnitude in carrier concentrations. For as-deposited of the $\mathrm{ZnO}$ films, it is of the order of $5.65 \times 10^{19}$, whereas at the increase in temperature $150{ }^{\circ} \mathrm{C}, 200{ }^{\circ} \mathrm{C}, 250{ }^{\circ} \mathrm{C}$, and $300{ }^{\circ} \mathrm{C}$ it increases to a value of the order of $1.95 \times 10^{20}, 2.35 \times 10^{20}, 3.11 \times 10^{20}$, and $3.92 \times 10^{20}$ respectively. Found for each $\mathrm{ZnO}$ film that with increasing annealing temperature, the electron mobility and resistivity decreases, and carrier concentration increases.

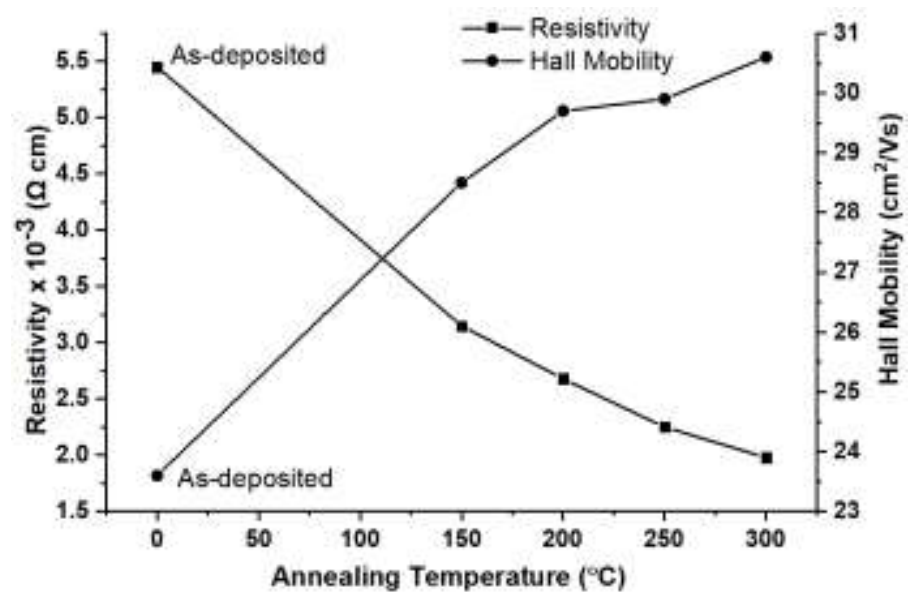

Figure 9: shown the resistivity of the $\mathrm{ZnO}$ thin film in the temperature range $150{ }^{\circ} \mathrm{C}, 200{ }^{\circ} \mathrm{C}, 250{ }^{\circ} \mathrm{C}$, and $300{ }^{\circ} \mathrm{C}$

Table 2. Carrier concentration, resistivity, and mobility of $\mathrm{ZnO}$ thin films with variant annealing temperature by OTA technique

\begin{tabular}{cccc}
\hline $\begin{array}{c}\text { Annealing } \\
\text { Temperature }{ }^{0} \mathrm{C}\end{array}$ & Resistivity $\times 10^{-3}(\Omega \mathrm{cm})$ & $\begin{array}{c}\text { Carrier concentration } \\
\left(\mathrm{cm}^{-3}\right)\end{array}$ & Hall Mobility $(\mathrm{cm} 2 / \mathrm{Vs})$ \\
\hline As-deposited & 5.45 & $5.65 \times 10^{19}$ & 23.6 \\
150 & 3.15 & $1.95 \times 10^{20}$ & 28.5 \\
200 & 2.68 & $2.35 \times 10^{20}$ & 29.7 \\
250 & 2.25 & $3.11 \times 10^{20}$ & 29.9 \\
\hline 300 & 1.98 & $3.92 \times 10^{20}$ & 30.6 \\
\hline
\end{tabular}

\section{Estimated cost}

The economic cost is a term in which the sum of the value of materials, labor, and other direct and indirect costs of a given product is paid. The direct costs are that pay to trade off the product such as the $\mathrm{ZnO}$ material, the glass substrate, and the amount of gas. Indirect costs are the amounts paid to produce, such as the electrical current consumed in annealing processes and the consumption of devices. In general, indirect costs cannot be loading it to the value of the sample. Therefore, the purpose of the cost study is a compared with the sample cost at the same results of the physical properties for the different annealing processes.

There is no need to discuss the cost of preparing the $\mathrm{ZnO}$ thin film because it is a fixed cost. This study will be a focus on comparing the cost of the consumption power (watt) in the OTA technique with other annealing techniques. This study also includes the cost of the heat treatment processes only of the $\mathrm{ZnO}$ thin film sample. The $\mathrm{ZnO}$ thin film heat treatment process by the OTA technique is developed successfully at the required temperatures. The transparency and resistivity of the samples treated by OTA processes compared with those of other researchers. Tables 3 and 4. Show compares electrical and optical properties at the thermal annealing process with 
other techniques at $300{ }^{\circ} \mathrm{C}$. The resistivity of the $\mathrm{ZnO}$ thin film changing after heat treatment by the OTA technique from $5.45 \Omega . \mathrm{cm}$ to $1.98 \Omega . \mathrm{cm}$. While the transmittance of $\mathrm{ZnO}$ thin films changing after heat treatment by the OTA technique from $71.86 \%$ to $94.92 \%$. The heat treatment by the OTA technique compared to others is very simple.

Table 3. Show the resistivity of the $\mathrm{ZnO}$ thin film before and after treated by OTA processes at $300{ }^{\circ} \mathrm{C}$ compared with those of other researchers.

\begin{tabular}{lcccc}
\hline $\begin{array}{c}\text { Technique } \\
\text { type }\end{array}$ & $\begin{array}{c}\text { Consumption } \\
\text { power (watt) }\end{array}$ & $\begin{array}{c}\text { Resistivity } \times 10^{-3} \\
(\Omega \mathrm{cm}) \text { before heat } \\
\text { treat }\end{array}$ & $\begin{array}{c}\text { Resistivity } \times 10^{-3} \\
(\Omega \mathrm{cm}) \text { after heat } \\
\text { treat }\end{array}$ & Reference \\
\hline OTA & $\mathbf{8 0 0}$ & $\mathbf{5 . 4 5}$ & $\mathbf{1 . 9 8}$ & Our study \\
$\begin{array}{c}\text { Quartz furnace } \\
\text { in nitrogen gas } \\
\begin{array}{c}\text { Quartz furnace } \\
\text { in air }\end{array}\end{array}$ & 2500 & 1.26 & 1.05 & {$[13]$} \\
$\begin{array}{c}\text { Quartz furnace } \\
\text { in vacuum }\end{array}$ & 2000 & 6.7 & 5.5 & {$[16]$} \\
\hline $\begin{array}{c}\text { Quartz furnace } \\
\text { in ambient } \\
\text { atmosphere }\end{array}$ & 2500 & 3.68 & 2.85 & {$[18]$} \\
\hline
\end{tabular}

Table 4. Show the transparency of the $\mathrm{ZnO}$ thin film before and after treatment by OTA processes at $300{ }^{\circ} \mathrm{C}$ compared with those of other researchers.

\begin{tabular}{ccccc}
\hline $\begin{array}{c}\text { Technique } \\
\text { type }\end{array}$ & $\begin{array}{c}\text { Consumption } \\
\text { power (watt) }\end{array}$ & $\begin{array}{c}\text { transmittance } \% \\
\text { before heat treat }\end{array}$ & $\begin{array}{c}\text { transmittance } \% \\
\text { after heat treat }\end{array}$ & Reference \\
\hline $\begin{array}{c}\text { OTA } \\
\text { Quartz furnace } \\
\text { in air }\end{array}$ & $\mathbf{8 0 0}$ & $\mathbf{7 1 . 8 6}$ & $\mathbf{9 4 . 9 2}$ & Our study \\
$\begin{array}{c}\text { Quartz furnace } \\
\text { in vacuum }\end{array}$ & 2000 & 63 & 67 & {$[14]$} \\
$\begin{array}{c}\text { Quartz furnace } \\
\text { in air }\end{array}$ & 2500 & 85 & 87 & {$[15]$} \\
\hline $\begin{array}{c}\text { Quartz furnace } \\
\text { in air }\end{array}$ & 2000 & 80 & 90 & {$[16]$} \\
\hline
\end{tabular}

\section{Conclusion}

In this paper, $\mathrm{ZnO}$ thin films were deposited by the PLD technique. The effects of heat treatment by the OTA technique on the physical properties of the $\mathrm{ZnO}$ thin films were investigated. The results show that prepared $\mathrm{ZnO}$

film has a hexagonal structure, and the film deposited at room temperature grows preferentially along the (002) crystal plane. As the annealing temperature increases, the physical properties improving. The characteristics of the $\mathrm{ZnO}$ film are best improving when the annealing temperature at $300^{\circ} \mathrm{C}$, compared with others temperatures. The heat-treated effect on the $\mathrm{ZnO}$ film by the OTA technique gave crystal quality and transmittance characteristics to be flat and transparent. In Addition, the improvement of electrical properties through a decrease in the resistivity and the forbidden bandwidth is $3.28 \mathrm{eV}$. 


\section{Acknowledgments}

This work was supported in part by the Thin Film Laboratories of the University of Technology / Department of Applied Sciences/ Branch of Laser Science and Technology.

\section{Conflict of Interest:}

The authors declare that they have no conflict of interest.

\section{References}

[1] HE Jianting, Z. Huizhao, XUE Chengshan, W. Shuyun, et al., "Effect of substrate temperature on microstructural and optical properties of $\mathrm{ZnO}$ films grown by pulsed laser deposition," Journal of the RARE METALS, Vol. 25, No. 2, p. 161, 2006.

[2] D. M. Bagnall, Y. F. Chen, Z. Zhu, T. Yao, S. Koyama, et al., "Optically pumped lasing of ZnO at room temperature," Applied Physics Letters, vol.70, p.2230, 1997.

[3] P. Dhamodharan, C. Manoharan, S. Dhanapandian, M. Bououdina, et al., "Preparation and characterization of spray deposited Sn-doped ZnO thin films onto ITO subtracts as photoanode in dye sensitized solar cell," Journal of Materials Science: Materials in Electronics, vol. 2(1), p.10-28,2015.

[4] V. Craciun, S. Amirhaghi, D. Craciun, j. Elders, et al.," Effects of laser wavelength and fluence on the growth of $\mathrm{ZnO}$ thin films by pulsed laser deposition,"Applied Surface Science, vol.86, p.99-106, 1995.

[5] B. Jasim, E, Ali,"Enhanced Production of Fibrinolytic Enzyme from Pseudomonas aeruginosa by Optimization Media Components," Journal of Applied Sciences and Nanotechnology, vol.1, no. 2, P. 58-65, 2021.

[6] E. M. Kaidashev, M. Lorenz, H. von Wenckstern, A. Rahm, H.-C. Semmelhack et al.," High electron mobility of epitaxial $\mathrm{ZnO}$ thin films on c-plane sapphire grown by multistep pulsed-laser deposition," Applied Physics Letters, Vol.82, p.3901, 2003.

[7] N. Üzar,"Investigation of detailed physical properties and solar cell performances of various type rare earth elements doped ZnO thin films," Journal of Materials Science: Materials in Electronics, vol.29, p.10471$10479,2018$.

[8] M Suchea, S Christoulakis, M Katharakis, N Katsarakis, et al.," Surface characterization of ZnO transparent thin films," Journal of Physics: Conference Series, vol. 10, p.147-150, 2005.

[9] R. A. Saleh, O. N. Salman, M. O. Dawood,"Physical Investigations of Titanium Dioxide Nanorods Film Prepared by Hydrothermal Technique," Journal of Applied Sciences and Nanotechnology, vol. 1, no. 3, P. 32 41,2021 .

[10] S. Venkatachalam, Yoshinori Kanno, and S. Velumani," Characterization on pulsed laser deposited nanocrystalline ZnO thin film,s" Journal of the Vacuum, vol.84, p.1199-1203, 2010.

[11] E. T. Salem, R. A. Ismail, M. A. Fakhry,and Y. Yusof, "Reactive PLD of ZnO thin film for optoelectronic application," international journal nanoelectronics and materials, vol.9, p.111-122, 2016.

[12] M. Qasim, J. Al-Dabbagh, N. M. Ahmed, V.G. Chigrinov, et al.," Oil thermal annealed nano-structured indium tin oxide thin films for display applications," journal of the SID 22/4, vol.22, P.187-190,2014.

[13] T. Prasada, M. C. Santhosh Kumar, and V. Ganesan, "Effect of annealing on the structural, optical and electrical properties of $\mathrm{ZnO}$ thin films by spray pyrolysis," Journal of Indian J. Phys., Vol. 85, No. 9, p. 13811391, 2011.

[14] I Li, F. Liang, C. Ximing, L. Gaobin, LIU Jun, et al., "Effect of annealing treatment on the structural, optical, and electrical properties of Al-doped ZnO thin fiis," journal of RARE METALS, Vol. 26, No. 3, p. 247, 2007.

[15] S. Cui, Chengyou Liu, and Xiaotian Li, "The Effect of Annealing Heat Treatment on Structural and Optical 
Properties of ZnO Thin Films," Advanced Materials Research, Vol. 926-930, p. 274-277, 2014.

[16] M. H. Abdullah, and M. H. Mamat,"Effects of Annealing Treatment on the Properties of TiO2/ZnO Thin Film Prepared by Simultaneous RF-Magnetron Sputtering," Advanced Materials Research, Vol. 832, p.573578, 2014.

[17] K. Nadarajah, C. Y. Chee, and C. Yong Tan," Influence of Annealing on Properties of Spray Deposited ZnO Thin Films," Journal of Nanomaterials, Vol. 2013, p.8, 2013.

[18] M. M. El-Desoky, M. A. Ali, G. Afif, and H. Imam," Annealing effects on the structural and optical properties of growth $\mathrm{ZnO}$ thin films fabricated by pulsed laser deposition (PLD)," Journal of Materials Science: Materials in Electronics, vol.25(11),p.1-7,2014 .

[19] B.J. Jin, S.H. Bae, S.Y. Lee, and S. Im, "Effects of native defects on optical and electrical properties of ZnO prepared by pulsed laser deposition," Materials Science and Engineering, vol. B71, p. 301-305, 2000.

[20] F.K. Shan, Z.F. Liu, G.X. Liu, W.J. Lee, et al., "Aging and Annealing Effects of ZnO Thin Films on GaAs Substrates Deposited by Pulsed Laser Deposition," Journal of Electroceramics, vol. 13, p.195-200, 2004. 